\title{
How to Grow a Wildland: The Gardenification of Nature ${ }^{+}$
}

\author{
Daniel H. JANZen \\ Department of Biology, University of Pennsylvania \\ Philadelphia, PA 19104, USA. E-mail address: djanzen@sas.upenn.edu
}

\begin{abstract}
A core reality in wildland conservation is "Use it or lose it". And when you use it, something has to restore it. Footprints must mostly erase, or the use is not sustainable. The Area de Conservacion Guanacaste (ACG) in northwestern Costa Rica is a 3-decade old and long-term pilot project in tropical wildland biodiversity development and tropical wildland ecosystem development. In summary, it is environmental services development. Some conclusions are already evident:

- Restoring complex tropical wildlands is first and foremost a social endeavor; the technical issues are far less challenging.

- Survival of a large complex wildland, whatever its origin, in the face of humanity's genes and domesticated genomic extensions, requires a major paradigm shift-we cannot afford to perceive the conserved area as "wild", otherwise known as "up for grabs".

- Sustainability of a large wildland will only be achieved by bestowing garden status to it, with all the planning, care, investment and harvest that implies.

- All use is impact, all gardens are impacted-restoration is footprint absorption by the garden and occurs at all scales.

- Planning, care, investment and harvest within the wildland garden is achieved through detailed understanding of biodiversity and its ecosystems, AND in simultaneous incorporation of a specific garden's social milieu at local, national and international scales.

- The "achievable" is an ever-shifting and ever-negotiating n-dimensional hyperspace produced by the intrinsic traits of a specific wildland interwoven with the mosaic of social energies and agendas brought to bear on it.
\end{abstract}

\section{INTRODUCTION}

$\mathbf{W}$ e can approach the conservation of complex tropical wildlands from the top down, or we can arrive from the bottom up. Both roads lead to the same ndimensional wild hyperspace. Both roads are full of mudholes, detours, highwaymen, magnificent vistas and long boring stretches. And for any wildland that is to be conserved into perpetuity, both roads must be traveled.

\footnotetext{
${ }^{+}$Adapted from Raven P. and Williams T., eds. Nature and Human Society: The Quest for a Sustainable World. Proceedings of a conference, 27-30 October 1997, National Academy of Sciences, Washington, DC. National Academy Press, Washington, DC (in press), 1998. Reprinted here with permission of the US National Academy of Sciences.
}

In late 1985, driven by experiences with 1,500 gold miners invading Costa Rica's Parque Nacional Corovado, and by the concern of the Australian government as to "what to do with" their immense northern (dry) tropics, Winnie Hallwachs and I chose to arrive from the bottom up. It was what we felt the most familiar with as tropical field biologists. We applied the Australian question to a small national park in northwestern Costa Rica, Parque Nacional Santa Rosa, and we found that the reply contained the answer to the Corcovado question of how to avoid the invasion.

Here, I begin with the bottom up road, and finish with a quick view of the road from the top down. These views are generated by these 12 years of travel. In keeping with the dynamic nature 
of all gardens, wildland or otherwise, these views will evolve with future input.

\section{The BotToM UP VIEW}

The first fund-raising leaflet, produced in a kitchen and nurtured by The Nature Conservancy and two spacey academics, was titled "How to Grow a National Park". Its cover was a cow pat with a newly germinated guanacaste tree seedling in the middle. In 1985, tropical conservation fund-raising centered on the argument that we must buy forest urgently, because once it is cut down it is gone forever. Without denying this, we simultaneously argued that tropical dry forest could be restored. While tropical dry forest had once covered at least half of the forested tropics, human settlement had so thoroughly eliminated it that the only option was restoration through buying up trashed remnants somewhere to restore a portion large enough to conserve an entire dry forest ecosystem. That "somewhere" focused on Santa Rosa's 10,600 ha because we were familiar with it and because the raw materials appeared to be there. The idea survived and grew because the Costa Rican community believed in it and worked for it, and because the international community was willing to pay cash and sweat equity for the existence value of tropical nature.

In 1989, the idea became the Area de Conservacion Guanacaste (ACG; http:// www.acguanacaste.ac.cr), which is how I will refer to it. The operational word was "restore". The nitty-gritty place-based question was how to severely diminish four centuries of footprints by modern society, and let the forest take back its land. We called it restoration biology and biocultural restoration. It was also secondary succession, regeneration, regrowth, reforestation, aforestation, farming, ranching, mitigation, recuperation, recovery, rehabilitation and sustainability.

How to restore this particular tropical dry forest? Simultaneously

- stop the anthropogenic fires,

- restore the size,

- integrate its socio-economics with the neighbors at all scales,

- pay the bills.

\section{Stop anthropogenic fires}

This particular tropical dry forest does not have non-anthropogenic fires. We were not confronted with the dilemma of deciding when to let it burn. The lands of the ACG have survived four centuries of clearing forest and brush by repeated annual to semi-annual anthropogenic fires during the sixmonth dry season. The 120,000 ha of the ACG contained at least 50,000 ha of highly inflammable old pastures and brushy fields in 1985 . Every time a fire passed through it, more woody vegetation was eliminated and replaced with introduced African pasture grasses. However, the region had not been sufficiently successful to be a thoroughly cleared agroscape. Without fire, the forest remnants sprinkled over the de-forested areas would expand to restore the forest. Every farmer and rancher knew this, though biologists and conservationists were much more skeptical.

But stopping the fires was not a technical issue nor a biological question. The methods were straightforward: apply trucks, tractors, pumps, radios and walkie-talkies, burned firebreaks, fire lookouts, and lots and lots of brooms. Stopping the fires was a personnel management question. It was a question of motivation. It was a question of being there at 2 am on Easter Sunday when your family and friends are at the beach, of working all night to extinguish a fire in the cool and the windless dark, of maintaining a lookout for six months for 24 hours a day. It was a question of working with the neighbors, of having the neighbors be part of the fire crew by not setting the fire in the first place.

Elimination of the fire footprint was achieved by selecting about a dozen locally-hired staff, giving them the entire responsibility, backing their budgetary needs, and giving them the opportunity to invent any schedule, any administration. This included going off-site to combat fires on private neighboring land, included strongly supporting a region-wide education program about the value of fire elimination, and included calling on the regional police force and other volunteers when a particular fire got out of hand. The ACG Fire Program, and the ACG administration as a whole, did it. Today, the brushy ACG pastures and their interdigitated dry forest remnants are essentially fire-free and display at least 40,000 ha of rapidly regenerating young forest. The seeds arrive by water, wind, birds, bats, rodents, ungulates and carnivores. However, lest this appear glibly rosy, I should note that forest restoration of the abandoned rainforest pastures in the eastern wet end of the ACG is proceeding much more slowly. It takes plowing, and planting, and people. Wet 
forest pastures are a different and more difficult story, and the contrast emphasizes tropical diversity of conservation as well as biology.

Fire control underlines the complexity of management of the wildland garden. In the late 1970s, when Santa Rosa was still very much a semi-conserved tiny island of fragmented forest in a great sea of agroscape, there were more than 2,000 semi-feral cattle in its 10,600 ha. Fires burned across virtually all of it every annual dry season. But it was a relatively stable mosaic of pasture and forest fragments, as it had been for centuries. Then, in a spate of classical national park management in 1977, the cattle were removed but no fire control program put in place. The introduced African pasture grasses then grew two meters high, and their fuel for the annual fires began the steady process of thorough removal of the remaining forest fragments. The lesson was obvious.

The young ACG left the cattle on the pastures as the land was purchased in the mid-1980s. At times it even rented browsing rights to as many as 7,000 additional cattle. They were biotic mowing machines. They kept the grass down as the nascent fire control program came into its own. And the newly fire-free and cattle-rich pastures filled even more rapidly with woody, shade-producing plants than did those without livestock. So, why not leave the cattle until full reforestation? Biotic mowing machines are not free. Their footprint is the trashing of the streams, rivers and riparian vegetation, unless they are fenced out of them at a cost greater than their market value. However, just to emphasize how complex is the issue, I should note that a muddy dry season waterhole with a horse or cow standing in it is a photograph of the neotropical "natural" before the Pleistocene hunters and their carnivore helpers extinguished our megafauna 9,000 years ago. The evèntual ACG dry forest will probably have a sector that contains whatever Pleistocene megafauna can be recuperated.

However, the wildland garden is not humanity free and never can be. The Pleistocene hunters left their indelible footprints on every square meter of the New World. More trampling by humanity has occurred every year since. "Wildland" refers to the fact that the species that are there, that have survived, and their relationships to each other, by-and-large come about through letting them bash each other over the head and eat as they will, without being planted in neat rows and put in temperature controlled chambers during the winter or dry season. We can remove the anthropogenic fires, but we cannot remove the edge effects, the insularization, the pesticide rain, the light contamination, the diminution of migrants, the global warming....

\section{Restore the size}

How big would be big enough? Parque Nacional Santa Rosa was a 10,600 ha island, a portion of one of Costa Rica's first ranches, started about 1580. It held a ghost of the dry forests that once extended from the foothills behind Mazatlan, Mexico, to southern South America, with a rain forest perturbation here and there. What once was that dry forest is now much of the neotropical agroscape, and humanity is not about to give it back to nature. All surviving neotropical dry forests are islands in that agroscape.

Santa Rosa was far too small for the survival of its ecological processes, of its dry forest ecosystem. It contained only pieces of drainage basins, only small portions of major habitats, only part of the contour, and it was virtually all edge. Most of the deforested parts were covered with African pasture grasses, tall and rank without their biotic mowing machines. It was far too small to absorb the many kinds of human footprints that would result from becoming a local, national and international wildland garden. And, especially, it needed to expand to the wetter east. Much of its more mobile dry forest biodiversity-the insects and the birds-seasonally migrated to the rain forests and cloud forests at and across the mountains to the east, and returned for the sixmonth rainy season.

The ACG expanded until the dry forest was big enough and until it contained its dry season lifeboats at the eastern end. The border was not set by biology but by the reality of social resistance. The ACG expansion stopped where the very profitable portions of the agroscape began. This expansion incorporated other semi-conserved wildland islands (Sector Murcielago, Reserva Forestal Orosí, Parque Nacional Rincon de la Vieja, Refugio de Vida Silvestre Isla Bolaños). All the private lands in between these fragments - some 80 of them-were purchased, ranging from small farms to large ranches, from squatters to absentee landlords and land speculators. And it extends a modest $6 \mathrm{~km}$ out into the Pacific Ocean.

On the one hand, large-scale land purchase was greatly facilitated by a rapid demise of the region's cattle industry during the same decade, 
by the overall low quality of the regional agroscape, by Central American military turmoil, and by the socio-economic reality that virtually all owners were willing to convert their land into more profitable ventures elsewhere. A major contribution was also the moderate number of Costa Rican and foreign owners who felt that it was highly respectable to have their lands become "national park" and thus accept the minimalist prices that the conservation community pays for existence value.

On the other hand, buying private properties and displacing their employees intertwined the ACG inextricably, once and for all, with its neighbors. Ranch and farm houses became ACG infrastructure, and even dwellings of former employees when they or their neighbors were hired as new ACG staff. Their children were among the pupils in the ACG Biological Education Program. ACG staff bought in their stores. And the local decision-makers became the ACG board of directors (Comité Local), a responsibility and opportunity shared with the Ministry of the Environment and Energy (MINAE) and the ACG staff itself. The process of building the ACG was intrinsically, from the start, an act of establishing presence and an act quite different from gazetting a large pristine wildland as a national park.

And as the area of the ACG increased, so did the opportunities for presence and socio-economic integration. When a vandal sets a fire that burns 2,000 ha of centuries-old African grass pasture, it is a thin scar on the ACG landscape, not the end of a project. If a deer is poached, it can often be shrugged off. When a soccer field or a picnic ground, is needed, the land is there. When the school children trample these ten ha, they can then trample those ten ha while the first ten ha recuperate. If you need 20 ha of pasture as fuel for the ACG work horses, well, there it is. Become a biodegrader for 1,000 truckloads of orange peels a year? Build a new road for management? Put up a wind farm? Host an ecotourism program? Seeds for a mahogany seed plantation? Grow a carbon crop? Build an internet Yellow Pages for 235,000 species? Somewhere in 120,000 ha such footprints can often be absorbed. In 10,000 ha they rarely are. The "use" of the wildland garden does need to be for the most part non-damaging.

And today, unforeseen before 1992, the expansion of the ACG into the terrain of the eastern rain forests and cloud forests has become part of the conservation solution to the impact of the drying and heating that the western ACG dry forests are suffering through global warming. 1997 was the driest and hottest year in the 22 years of recorded weather in the ACG. The rain forests and (cooler) cloud forests to the east are a lifeboat for the dry forest on more than the scale of seasonal migrations.

\section{Integrate its socio-economics with the neighbors at all scales}

The ACG is a 120,000 ha wildland garden with 130 owner-employees, a $\$ 1.6 \mathrm{~m}$ annual operation budget, and 3.3 million stockholders-all of Costa Rica. It operates within the bylaws of incorporation of the state, and more specifically, within those of the Ministry of the Environment and Energy (MINAE). The ACG macroproduce is the conservation of its wildland biodiversity and its ecosystems into perpetuity. The process that realizes this goal is to be a major player in the national and local biodiversity industry, intertwined with the ecosystem industry: biodiversity development, ecosystem development, environmental services development. This process calls for the unending quest for uses that are non-damaging. However, all uses do leave fingerprints and footprints. The ACG has come to peace with the reality that $5 \%$ of biodiversity and ecosystems will be sacrificed to guarantee the remainder. This is the ACG wildland peace treaty that is being negotiated with the agroscape and the urban landscape with which it is integrated.

Such socio-economic integration at local, national and international scales is sought through very diverse activities. The conservation area garden has its public reading rooms, its stacks, and its rare book cage, with different rules for each. A few examples:

- As the regional cattle industry has died over the past decade, the ACG's biodiversity industry and ecosystem industry has become part of regional economic restoration-notonly through cash flow but through the offering of relatively ceiling-free and diverse job opportunities that are far more in tune with modern society than was herding livestock and subsistence farming. The small neighboring town of Quebrada Grande is rapidly evolving from a cowboy's shopping center to a suburb for the ACG and yet more urban activities in the regional capital, Liberia. All ACG employees are Costa Rican and $82 \%$ from the immediate region. $42 \%$ are women. All are 
computerizing, all are networking, all are exploring this new world of employment under the ethic of professional responsibility toward a goal-and the pain and opportunities that these forces bring. A parataxonomist is far more upward mobile and occupationally flexible than is a cowboy.

- Since 1987 the ACG Biological Education Program has taught basic biology in the ACG wildland habitats to all 4th, 5th and 6th grade students, and now high school students, who live in the vicinity of the ACG. This is today 42 schools and more than 2,000 students peryear$12 \%$ of the ACG annual operating budget. The goal is biocultural restoration and bioliteracy. It is widely rumored that the ACG "has it easy" because it is imbedded in a "tame populace". I wonder why it is tame.

- By restoring the original forest vegetation throughout the ACG, the watersheds are being restored for 11 major rivers that service all local towns and service the irrigation systems for major agroscapes. This ACG water factory is becoming particularly crucial as global climate warming continues to heat up and dry out the region, and as the region's agriculture moves towards explicit environmental control.

- By restoring the original forest vegetation throughout the ACG, atmospheric carbon is being farmed (and see Costa Rica's P.A.P. in http://www.ji.org and http://www.unfccc.de). The ACG with its biodiversity and ecosystem industry then becomes both a living and green smokestack scrubber, and the assurance policy that the newly sequestered carbon stays there. Carbon farming is not only forest restoration, but also the carbon purchase can contribute to operational costs and investment capital for a conserved wildland. Just as tropical "debt-fornature swaps" did not solve a nation's debt problems yet fueled some major conservation initiatives, carbon farming in conservation areas will not solve our greenhouse gas problem but certainly can contribute to its holistic solution. Forest fragmentation and habitat reduction is the single largest threat to tropical biodiversity today. Carbon farming at strategically located points can reduce both trends. And this in turn brings up the many imaginative ways that the sequestered carbon can even be harvested and parked elsewhere in buildings, furniture and even underground deposits. A wildland tree becomes a long term $\mathrm{CD}$. Carbon harvest and wind-throws begin to merge in the nature of their footprints.

- The ACG has been a major stimulus, supporter, training ground and proving ground for many of the activities in the field by the Instituto Nacional de Biodiversidad (INBio), the institution that has accepted major responsibility in the Costa Rican national biodiversity inventory, bioliteracy, and computerization of biodiversity management (http:/ / www.inbio.ac.cr). Locally-hired and -trained ACG and INBio parataxonomists and parabiodiversity prospectors share ACG facilities. These paraprofessionals are part of the intellectual and operational critical mass that carries forward the ACG Research Program. The international taxonomic cleanup swirling around INBio's national biodiversity inventory, in great part being carried forward by the nation's parataxonomists, is key to readying the taxonomic platform on which the ACG's biodiversity industry is based. At least $65 \%$ of Costa Rica's estimated half million species occur in the ACG's $2 \%$ of the country. A growing biodiversity Yellow Pages on the ACG web site is anticipated as the 1998 debut for these species.

- The ACG grew out of Costa Rica's second oldest national park and the country's second oldest ranch, the latter established in the late 1500 s. It has been a major stimulus and supporter for the rapidly evolving Sistema Nacional de Areas de Conservacion (SINAC) of MINAE. SINAC is the administrative and technical integration of all of Costa Rica's conserved wildlands into 10 consolidated Conservation Areas. SINAC's wildlands constitute about $25 \%$ of the country and combine many classical management categories into one, informally called "save it by using it without destroying it". And ecotourism is Costa Rica's largest crop. The ecotourist-whether a school child, a visitor from Peoria, or a researcher-is a better kind of cow, and the Conservation Areas are the pastures. SINAC was founded to forge a peaceful coexistence between the wildland garden, and the agroscape and urban landscape. Nothing invites neighbor encroachment more than the impression of abandonment or disuse. Wildland biodiversity must have a national presence. It must be the owner of a national farm.

- The ACG is developing itself as a researchfriendly platform for all ilks, local to national to 
international. How many times does a spider monkey scratch its left armpit (in the morning)? What species of plants do the caterpillars of rainforest skipper butterflies eat? Clarify the species and genera of hundreds of species of water mites? What flowers do bats stick their heads into? Will a pharmaceutical company find its gold in a bottle of frozen baby ticks? How many Ridley's sea turtle eggs survive the vultures and the coyotes? Where are the species of plants in a montane cloud forest? How can Cladocera be used to lower the numbers of dengue-bearing mosquitoes? Do the ACG parasitic wasps depress the leaf miner density in the neighbor's orange orchard? How many children do current ACG staff have and how many sibs did the parents have? How fast does an unburned pasture return to forest? How hard does the wind blow? The ACG is the place to find out. And this biodiversity and ecosystem research industry is not only a kind of very high-yield ecotourism, but each of these research projects carries with it the distant possibility of royalties-sometimes paid in fuel for the Biological Education Program, sometimes paid in votes by visitors, sometimes paid in cash from the pharmaceutical industry and other commercial users, sometimes paid in sweat equity by the researchers themselves.

- Even my presence on this podium describing a pilot project in complex tropical wildland survival is yet another box of tomatoes from this farm. But note that I am rapidly coming to be replaced by the net-see http:// www.acguanacaste.ac.cr

- My last example is a specific contract for biodiversity and ecosystem services between the ACG and Del Oro, a neighboring orange juice company. The ACG is being paid for 20 years of biological control agents, water, consulting, orange peel degradation, and isolation from orange pests. The payment is $\$ 480,000$ in the coinage of 1,200 ha of one of the biologically scarcest habitats in Costa Rica, the lowland transition forests between Atlantic rain forest and Pacific dry forest. And this mutualism has other ramifications in the form of Del Oro's "green" orange juice that is now certified Eco-OK by Rainforest Alliance, and made technically feasible through the abovementioned environmental services. This juice is penetrating the Costa Rica market, heading for the European and US market, and reinforcing the contemporary Costa Rican attitude of taking virtually its entire agroscape into sustainable development.

\section{Pay the bills}

Guarding a large box of gold under the bed can be done quite cheaply, and especially if no one but you knows that it is there-a little barbed wire, a gun, a watchdog. The annual operating budget for Parque Nacional Santa Rosa in the mid-1980s was about $\$ 120,000$ including salaries, most of which were spent elsewhere. This earliest wildland garden generated virtually no income for the region. Today.'s ACG is ten times as large, costs ten times as much to operate, and generates a diverse and large basket of cash and barter for the region. It meets its costs through a combination of payment for services and interest income from its endowment. This endowment was established in the late $1980 \mathrm{~s}$ through a combination of international donations for the existence value of the ACG, and government subsidy as a "debt-fornature-swap" for both existence value and sustainable development. The ACG future depends very heavily on being able to seek reasonable compensation for its biodiversity and ecosystem services to the public and commercial sectors, both independently and in consort with national-level and international-level projects. Yellowstone National Park's new landmark biodiversity prospecting agreement directly with Diversa Corporation in California (http:// www.wfed.org) is a most welcome sheep to the fold, as have been INBio's biodiversity prospecting contracts with Merck and the INBio-CornellBristol-Meyers Squibb ICBG project (http:// www.nih.gov/fic/ res/lessons.htm, http: / / www.nih.gov/fic/res/icbg.htm).

But being ten times as large as the original Santa Rosa should, and does, bring massive economy of scale to the ACG. Why then is the annual budget ten times as large? There are two reasons. First, the ACG is beginning to put its box of gold on the stock and bond market. This brings administration costs. An Internet web site is not a freebie. A fireman on call at 2 am levies inspiration costs. It costs to jolly a university-graduated Costa Rican biologist into making of lifetime of being a 5 th grade teacher in a remote rainforest town that is just today constructing its first gas station. Second, the tropics has a long-standing reputation for being a source of cheap labor. Well, when you move someone out of the pasture and the bean 
field, and onto the computer work station, into the national inventory, into the halls of politics, the operating cost per unit personnel skyrockets right into the "developed" world. "Local" is a geographic term that has very unfortunately gotten itself unconsciously synonymized with "compensation for services appropriate for a mule". As Costa Rica moves itself into being a sustainably developed country and realizes its human aspirations, its cost per citizen will be right up there with the rest of the developed world. That is what the word "development" means.

Ironically, we are today very concerned with internalizing environmental costs. The development of the ACG, and many other Costa Rican institutions, has made us all excruciatingly aware that internalizing biodiversity development costs and ecosystem service development costs will push budgets into figures not anticipated by the societies who stand to gain in both the short and long term. There is an enormous input of sweat equity and institutional subsidy in current taxonomy, biodiversity prospecting, wildland administration, political decentralization, wildland ecosystem engineering, and all the other things discussed here, and made explicit and implicit in such international agreements as the Biodiversity Convention and Climate Convention.

\section{Top Down VIEW}

The exportable generalizations that we academics and office-holders hold so dear are easily extracted from the above nitty-gritty. In doing all of the above, we were unconsciously creating a wildland garden and promoting peasant revolution. The traits of the ACG were and are driven by the organic traits of the site itself, themselves shaped by the goal of perpetual conservation. And they are shaped by the genetic hardwiring of humans to turn the world into more humans and their domesticated genomic extensions. And by the specific culture in which the ACG is embedded. And by the global humanity in which THAT is imbedded.

To generalize:

- Restoring complex tropical wildlands is first and foremost a social endeavor; the technical issues are far less challenging.

- Survival of a large complex wildland, whatever its origin, in the face of humanity's genes and domesticated genomic extensions, requires a major paradigm shift-we cannot afford to perceive the conserved area as "wild", otherwise known as "up for grabs".

- Sustainability of a large wildland will only be achieved by bestowing garden status to it, with all the planning, care, investment and harvest that implies.

- All use is impact, all gardens are impactedrestoration is footprint absorption by the garden and occurs at all scales.

- Planning, care, investment and harvest within the wildland garden is achieved through detailed understanding of biodiversity and its ecosystems, AND in simultaneous incorporation of a specific garden's social milieu at local, national and international scales.

- The "achievable" is an ever-shifting and evernegotiating n-dimensional hyperspace produced by the intrinsic traits of a specific wildland interwoven with the mosaic of social energies and agendas brought to bear on it. There is no all-purpose formula other than the pursuit of the goal itself.

Put another way, use it or lose it. And when you use it, something has to restore it.

Acknowledgments-The experiences and observations that have led to the above reflections have been generously supported for 34 years by the US National Science Foundation, the international scientific and academic community, and the government and people of Costa Rica. More specifically, the personnel of the Area de Conservacion Guanacaste (ACG), the Instituto Nacional de Biodiversidad (INBio), the Fundacion de Parques Nacionales (FPN) and the Ministerio del Ambiente y Energia (MINAE) have provoked and facilitated these thoughts. I wish to particularly thank the Costa Rican team of Alvaro Umaña, Rodrigo Gámez, Alvaro Ugalde, Mario Boza, Alfio Piva, Pedro Leon, Luis Diego Gomez, Rene Castro, Randall Garcia, Johnny Rosales, Luis Daniel Gonzales, Karla Ceciliano, Jose Maria Figueres, Maria Marta Chavarria, Roger Blanco, Angel Solis, Isidro Chacon, Nelson Zamora, Jorge Corrales, Manuel Zumbado, Eugenia Phillips, Jesus Ugalde, Carlos Mario Rodriguez, Alonso Matamoros, Jorge Jimenez, Alejandro Masis, Ana Sittenfeld, Felipe Chavarria, Julio Quiros, Jorge Baltodano, Luz Maria Romero and Sigifredo Marin, and all of the INBio parataxonomists, for particularly insightful and inspirational input over the last 12 years of development of these ideas. While it is clear that the international cast of contributors to a concept 
of this nature is enormous, I wish to particularly thank Kenton Miller, Peter Raven, Tom Eisner, Jerry Meinwald, Ed Wilson, Don Stone, Paul Ehrlich, Hal Mooney, Kris Krishtalka, Jim Edwards, Gordon Orians, Monte Lloyd, Mike Robinson, Steve Young, Preston Scott, Leif Christoffersen, Odd Sandlund, Mats Segnestam, Eha Kern, Bernie Kern, Hiroshi Kidono, Frank Joyce, Ian Gauld, Jon Jensen, Murray Gell-Mann,
Steve Viederman, Staffan Ulfstrand, Carlos Herrera, Steve Blackmore, Meridith Lane, Jim Beach, John Pickering, Amy Rossman, Bob Anderson, Terry Erwin, Don Wilson, Diana Freckman, Chris Thompson, Marilyn Roossnick, Luis Rodriguez, Dan Brooks, Charles Michener, Bob Sokal, John Vandermeer, Jack Longino, Rob Colwell, Chris Vaughan, and Tom Lovejoy for their investments of sweat equity in this process. 